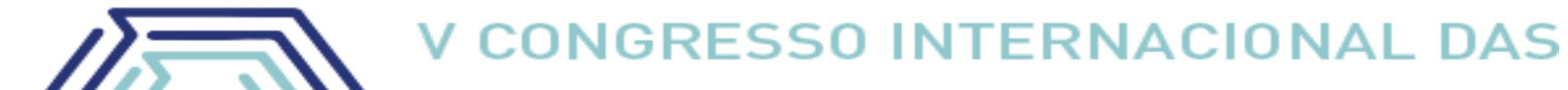 LICENCIATURAS COINTER - PDVL 2018
}

\section{CARREIRA DOCENTE EM QUÍMICA: VISÃO DE ESTUDANTES DO TERCEIRO ANO DO ENSINO MÉDIO}

\section{TEACHER CARE IN CHEMISTRY: VISION OF STUDENTS OF THE THIRD YEAR OF MIDDLE SCHOOL}

\author{
Apresentação: Pôster \\ Wellington de Souza Ferreira ${ }^{1}$; Joyce Francielle dos Santos Araújo²; Cíntia de Abreu \\ Arruda $^{3}$; Rauã Bezerra da Silva ${ }^{4}$; Kilma da Silva Lima Viana ${ }^{5}$; \\ DOI: $\underline{\text { https://doi.org/10.31692/2358-9728.VCOINTERPDVL.2018.00187 }}$
}

\section{Introdução}

A educação, segundo Saviani (2000), é a única via de acesso à integração social para todos, e a única porta de saída da miséria para as camadas mais pobres da população. Baseado nisso, o professor tem a missão de mudar a sociedade, porque é o personagem principal da educação.

Porém, devido à desvalorização dessa área profissional, muitos docentes estão deixando de lecionar e muitos estudantes que estão prestes a cursarem um curso superior, não estão querendo cursar Licenciaturas, pois não querem ser professores. Mas, relacionado a Licenciatura em Química, a falta de professores formados nessa área em comparação as outras Licenciaturas ainda é maior.

Nesse sentido, é preciso conhecer os aspectos que contribuem para a evasão de professores formados em Química nas escolas do Ensino Médio principalmente, pois segundo Silva (2011), a Química é uma Ciência vital para a melhoria da qualidade de vida do ser humano, logo, é de suma importância a formação de professores nessa área do conhecimento.

Nesta perspectiva, a nossa pesquisa apresenta o seguinte questionamento: "Quais os aspectos que afastam os estudantes da carreira docente em Química?”. Portanto, para responder a esta pergunta, a nossa pesquisa teve como objetivo identificar os principais aspectos que

\footnotetext{
${ }^{1}$ Licenciatura em Química, IFPE - Campus Vitória de Santo Antão, <souza.wellington@gmail.com>

${ }^{2}$ Licenciatura em Química, IFPE - Campus Vitória de Santo Antão, <joycefranaraujo@ gmail.com>

${ }^{3}$ Pós-graduação em Educação em Ensino de Ciências e Matemática, UFPE - CAA, <cintiaarruda@ outlook.com>

${ }^{4}$ Licenciatura em química, IFPE - Campus Vitória do santo Antão, <rauabezerr@outlook.com>

${ }^{5}$ Doutora em Ensino das Ciências, UFRPE, kilma.viana@ vitoria.ifpe.edu.br
} 
afastam os estudantes da carreira docente em Química, através da utilização de um questionário, com oito $(\mathrm{n}=8)$ perguntas, com estudantes do $3^{\circ}$ ano do Ensino Médio.

\section{Fundamentação Teórica}

O Brasil apresenta um cenário preocupante sobre a escassez de professores na educação básica, dentre as quais, a área de ciências da natureza é uma das mais precárias (AGOSTINI; MASSI, 2017).

É notório que a questão do baixo status do professor da Educação Básica é um fator para a não atratividade da carreira docente e isso se agrava quando os próprios formadores atuam dessa forma, diminuindo a autoestima dos licenciandos e aprofundando o preconceito de que esta é uma função de menor valor, negligenciando a importância do trabalho desse docente para a formação dos cidadãos do país (LOUZANO et al, 2010 apud SÁ; SANTOS, 2011).

Nesse sentido, especificando a formação de professores em Química, temos que:

[...]o Estudo Exploratório sobre o Professor Brasileiro (Brasil/Mec/Inep, 2009) sistematizou os resultados do Censo Escolar da Educação Básica de 2007 e destacou que no Ensino Médio brasileiro a disciplina Química é ensinada por: profissionais da Química (38,2\%); profissionais de áreas afins $(17,4 \%)$; profissionais da Pedagogia $(5,5 \%)$; e profissionais de outras áreas $(38,9 \%)$.

Logo, é perceptível que o percentual de profissionais de áreas totalmente desvinculadas do conhecimento químico supera os profissionais formados em Química. Diante disso, Sgarbosa et al, (2014), destaca que a escolha para a licenciatura em Química, está atrelada a diversos fatores e não necessariamente ao interesse em seguir à docência, de modo que o licenciado em Química, podendo atuar em carreiras com melhores condições de trabalho e com maior retorno financeiro, acaba não seguindo a profissão docente.

Diante disso, o ensino de Química nos dias de hoje vem em declínio por conta de vários fatores, que cujos principais são: deficiência na formação do professor; baixos salários dos professores; metodologia em sala de aula ultrapassada; redução na formação de licenciados em Química; poucas aulas experimentais; e desinteresse dos alunos (SILVA, 2011).

Portanto, há necessidade de uma efetiva política nacional de formação e valorização dos profissionais da educação, que incorpore, além de elementos de valorização profissional vinculados à carreira, remuneração e condições de trabalho, uma articulação, mais institucionalizada, definindo as estratégias para a formação inicial e continuada e a valorização efetiva de todos os profissionais (AGUIAR; SCHEIBE, 2010).

\section{Metodologia}


Essa pesquisa apresentou uma abordagem qualitativa, com o objetivo de identificar os principais aspectos que afastam os estudantes da carreira docente em Química.

\section{a. Caracterização do campo de pesquisa}

A pesquisa foi desenvolvida na instituição de ensino Ginásio de Limoeiro Artur Correia de Oliveira (Instituição 1), localizada na cidade de Limoeiro e na EREM Professora Amélia Coelho (Instituição 2), ambas localizadas no estado de Pernambuco.

\section{b. Sujeitos da pesquisa}

Os sujeitos que participaram da pesquisa foram, $33(n=33)$ estudantes da (Instituição 1) e 25 ( $n=25)$ estudantes da (Instituição 2), do $3^{\circ}$ ano do Ensino Médio.

\section{c. Instrumentos e procedimentos da pesquisa}

Para coleta de dados, foi aplicado um questionário aos estudantes com o objetivo de identificar os principais aspectos que afastam os estudantes da carreira docente em Química.

\section{Questionário aplicado aos estudantes:}

(Q1) Qual a sua escolha profissional para o futuro?

(Q2) O que você acha da profissão de professor?

(Q3) Você é incentivado a ser professor?

( ) Sou muito incentivado ( ) Sou pouco incentivado ( ) Não sou incentivado Quem lhe incentiva?

(Q4) Você tem vontade ou gostaria de ser professor de Química? Justifique sua resposta.

(Q5) Dentre os cursos de licenciatura qual você mais se identifica?
( ) Língua Portuguesa
( ) Geografia
( ) Matemática
( ) História
( ) Química
( ) Sociologia
( ) Física
( ) Filosofia
( ) Biologia
( ) Inglês ou Espanhol

(Q6) Com relação aos conteúdos de QUíMICA você:

( ) Aprende com Facilidade ( ) Aprende com Dificuldade ( ) Não aprende (Q7) Se você "não aprende" ou "aprende com dificuldade" os conteúdos de Química, marque as alternativas que indicam os principais motivos.

( ) Tenho dificuldade com Matemática

( ) Tenho dificuldade em decorar muitas fórmulas

( ) Tenho dificuldade de entender as aulas do professor

( ) Tenho dificuldade com as aulas experimentais

( ) Tenho dificuldade em entender as questões das provas 
( ) Tenho outra dificuldade. Qual?

\section{Resultados e Discussões}

De acordo com os resultados do questionário aplicado aos estudantes de ambas as escolas observamos que referente a (Q1), nenhum dos estudantes tem como escolha profissional para o futuro a carreira de professor, pois 31 dos estudantes da instituição 1, responderam que gostariam de seguir como carreira profissional uma outra profissão, as mais citadas foram "direito, medicina, medicina veterinária e polícia" e 2 estudantes relataram que estavam indecisos. Já na instituição 2, 23 alunos também responderam seguir outra carreira, as mais citadas foram "enfermagem, odontologia, medicina e direito" e 2 dos estudantes não responderam. Diante desses dados, podemos perceber que grande parte dos jovens que estão concluindo o ensino médio não têm interesse para a carreira docente.

Referente a (Q2), mesmo os estudantes não escolhendo a carreira de professor como profissão futura, todos os mesmos relataram que acham essa profissão muito importante para a sociedade, como podemos ver em algumas frases abaixo:

“Muito importante, aliás todas as profissões dependem do professor”.

“Muito excelente, pois se não houvesse essa profissão, não haveria pessoas com formação".

"Uma profissão muito importante para a educação dos alunos."

"Pouco valorizada, mas é fundamental."

Dessa forma, mesmo os estudantes considerando importante a profissão de professor, mas por conta da desvalorização, da mesma nos dias atuais, muitos não querem segui-la. E essa desvalorização, segundo Melo (2016), está atrelada a diversos fatores, como: formação, condições de trabalho e remuneração.

Diante desse contexto, foi perguntado aos estudantes se eles são incentivados a seguir a carreira de professor, observamos na (Q3), que 5 estudantes disseram ser incentivados, 18 disseram receber pouco incentivo e 35 disseram não receber incentivo algum. Dentre os estudantes que relataram receber incentivos, 3 recebe de familiares e 2 de professores.

Já especificando na carreira docente em Química, observamos na (Q4), que os estudantes de ambas as instituições, em sua maioria disseram não ter interesse na carreira de professor de Química e responderam o seguinte:

"Acho uma profissão muito legal, mas não tenho interesse ".

"É legal, mas muito estressante por ser Química”.

"Acho uma área boa, mas não me interesso".

"Acho a profissão interessante, mas acho que não é a minha área”. 
Porém, entre os estudantes pesquisados, mesmo na questão 1, não escolhendo como primeira opção para a sua escolha profissional a carreira de professor, porém quando perguntado de forma específica se tinham interesse em ser professor de Química, três desses estudantes, relataram ter interesse em seguir, como podemos ver abaixo:

"Gosto muito da área e tenho interesse em segui-la".

"Gosto muito da matéria, por isso acho que seria um bom profissional”.

"É uma das minhas opções, pois amo a Química”.

Dessa maneira, mesmo que pouco, mas ainda tem estudantes com interesse em ser professor, e em Química principalmente, que é uma área que apresenta uma grande evasão de professores formados. Diante disso, é necessário que o governo valorize mais essa carreira, pois é de suma importância para a sociedade. E com isso haja mais incentivo dos próprios professores, principalmente, pois muitos deles não incentivam seus alunos a seguirem essa profissão, como foi observado na (Q3).

$\mathrm{Na}$ (Q5), sobre o curso de licenciatura que mais se identificam, dos 58 estudantes pesquisados das instituições 1 e 2, obtivemos os dados seguintes: 10 em Letras, 6 em Matemática, 3 em Química, 1 em Física, 9 em Ciência Biológicas, 5 em Geografia, 7 em História, 6 em Sociologia, 4 em Filosofia e 5 em Inglês ou Espanhol e 2 estudantes não responderam nenhuma das opções.

Logo, é perceptível que a Química é uma das disciplinas mais rejeitada pelos estudantes, ficando para traz apenas da Física. Um desses fatores está atrelado a grande dificuldade que a maioria dos estudantes encontram nessa disciplina, como podemos ver na (Q6), apenas 4 estudantes disseram aprender com facilidade os conteúdos da disciplina de Química, 40 relataram aprender com dificuldade e 14 dos estudantes não aprendem os conteúdos.

Essas dificuldades, baseado na (Q7), estão relacionadas aos seguintes fatores: 23 alunos têm dificuldade com matemática, 49 afirmaram ter dificuldade em decorar fórmulas, 21 têm dificuldade com as aulas do professor, 5 têm dificuldade com as aulas experimentais e 18 têm dificuldade com as questões da prova.

Baseados nesses dados, podemos apontar que a causa para essa grande rejeição da carreira docente, especificamente em Química, está relacionada com a desvalorização do magistério, mas também com a falta de profissionais capacitados para estarem nas salas de aula, visto que, uma grande parte do professores que lecionam a disciplina de Química, não são formados na área, o que consequentemente não contribui para o ensino-aprendizagem dos estudantes nessa área do conhecimento, o que faz com que os mesmo não queiram seguir a Licenciatura em Química como profissão para o futuro deles. 


\section{Conclusões}

Diante do exposto, podemos perceber que grande parte dos jovens que estão concluindo o ensino médio não têm interesse para a carreira docente, mesmo considerando importante essa profissão, porém, por conta da desvalorização da mesma nos dias atuais, atrelada as questões da formação, condições de trabalho e remuneração, muitos não querem segui-la.

Também foi perceptível que a Química é uma das disciplinas mais rejeitada pelos estudantes, ficando para traz apenas da Física. Observamos que um dos fatores para isso está atrelado a grande dificuldade que a maioria dos estudantes encontram nessa disciplina.

Logo, podemos concluir que a causa para essa grande rejeição da carreira docente, especificamente em Química, está relacionada com a desvalorização do magistério, mas também com a falta de profissionais capacitados para atuarem nas salas de aula.

\section{Referências}

AGOSTINI, G.; MASSI, L. Atratividade e permanência na carreira docente: um estudo sobre o encaminhamento profissional de licenciados em Química. In: XI Encontro Nacional de Pesquisa em Educação em Ciências - XI ENPEC, 2017, Florianópolis - SC. Anais do XI Encontro Nacional de Pesquisa em Educação em Ciências, 2017.

AGUIAR, M. A. S.; SCHEIBE, L. Formação e valorização: desafios para o PNE 2011/2020. Revista Retratos da Escola, v. 4, n. 6, p. 77-90, jan./jun. 2010. Disponível em: <http://retratosdaescola.emnuvens.com.br/rde/article/viewFile/70/62>. Acesso em: $01 \mathrm{de}$ setembro de 2018.

Estudo exploratório sobre o professor brasileiro, 2009. Disponível em: <http://portal.mec.gov.br/dmdocuments/estudoprofessor.pdf.> Acesso em 28 de setembro de 2018 .

MELO, D. S. Profissão docente: um estudo sobre a desvalorização/valorização da carreira. In: II Jornada Baiana de Pedagogia, 2016, Ilhéus/Ba. Anais da II Jornada Baiana de Pedagogia, 2016.

SÁ, C. S. S.; SANTOS, W. L. P. Licenciatura em Química: carência de professores, condições de trabalho e motivação pela carreira docente. In: Encontro Nacional de Pesquisa em Educação em Ciências, 2011, Campinas. Atas..., Campinas: ABRAPEC, 2011.

SAVIANI, O. Pedagogia histórico-crítica: primeiras aproximações. 7. ed. Campinas, SP: Autores Associados, 2000. 
SGARBOSA, E. C. et al. Motivações dos estudantes para o ingresso em um curso de Licenciatura em Química. In: Evento de Educação em Química, 2014, Araraquara: IQ/UNESP. Anais do Evento de Educação em Química, 2014.

SILVA, A. M. Proposta para tornar o ensino de química mais atraente. Revista de Química Industrial, $731,7-12,2^{\circ}$ trimestre de 2011. 